\title{
AVALIAÇÃO DA PERICULOSIDADE DA COSTA ROCHOSA DO MUNICÍPIO DO RIO DE JANEIRO: CONTRIBUIÇÃO PARA OS PLANOS DE SEGURANÇA E PREVENÇÃO DE ACIDENTES
}

\author{
Felipe Lima Campos Guimarães Miguel ${ }^{(a)}$ \\ (a)Departamento de Geografia - Instituto de Geociências - Universidade Federal do Rio de Janeiro (UFRJ), \\ felipegmiguel@yahoo.com.br
}

\section{Eixo: DINÂMICA E GESTÃO DE ZONAS COSTEIRAS}

\begin{abstract}
Resumo
Estudos sobre costas rochosas são de grande valia na elaboração de planos de segurança. A maioria dos acidentes nessas localidades costeiras é ocasionada pelo movimento de subida e descida das ondas nas superfícies rochosas, conhecido como lavagem, que acaba arrastando os usuários para o mar. Diante disso, o presente estudo busca, através de parâmetros geomorfológicos e oceanográficos, avaliar o grau de periculosidade de locais da costa rochosa do município do Rio de Janeiro utilizados para lazer. As faixas de atuação das ondas funcionaram como indicador dos alcances máximos atingidos pelas lavagens nos locais avaliados. A orientação frente às ondulações e a rugosidade de suas superfícies também serviram para avaliar o perigo oferecido. Os locais tiveram seu grau de periculosidade classificado como baixo, moderado, elevado e muito elevado. Espera-se que os resultados encontrados possam servir no auxílio de medidas preventivas e na redução de acidentes na costa rochosa do município.
\end{abstract}

Palavras chave: costa rochosa; ondas; periculosidade.

\section{Introdução}

Estudos sobre costas rochosas são de grande valia na elaboração de planos de segurança. Grande parte dos acidentes ocorridos nessas localidades costeiras é ocasionada pelo movimento de subida ("set up") e descida ("set down") das ondas nas superfícies rochosas, conhecido como lavagem ("wash"). São essas lavagens que acabam arrastando os usuários para o mar (Figura 1).

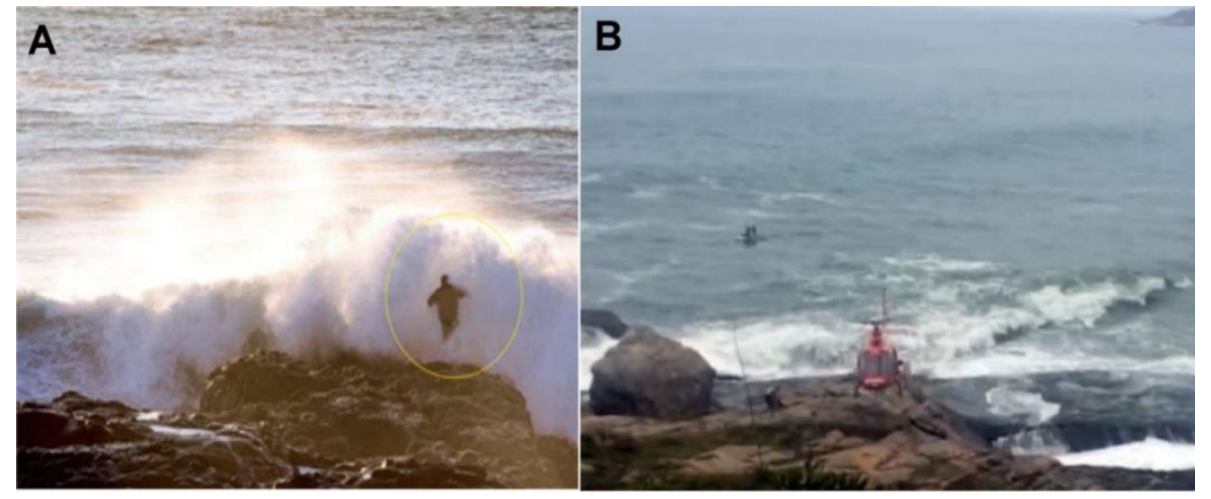

Figura 1: A) Lavagem das ondas arrastando usuário para dentro do mar; B) Resgate 


\section{OS DESAFIOS DA GEOGRAFIA FÍSICA NA FRONTEIRA DO CONHECIMENTO \\ Instituto de Geociências - Unicamp \\ Campinas - SP \\ 28 de Junho à 02 de Julho de 2017}

A lavagem, por sua vez, é influenciada pela rugosidade encontrada na superfície da costa rochosa, sua inclinação, largura e sua orientação frente às ondulações. A compreensão das relações existentes entre a geomorfologia desse ambiente costeiro com a magnitude da lavagem realizada pelas ondas possibilita localizar e identificar os locais considerados mais críticos com relação ao perigo oferecido aos usuários.

Neste contexto, o presente estudo busca avaliar o grau de periculosidade de diversos locais da costa rochosa do município do Rio de Janeiro, utilizados para lazer. Espera-se que o resultado desta pesquisa possa ser útil no auxílio de medidas preventivas e na redução de acidentes.

\section{2. Área de Estudo}

A costa rochosa do município do Rio de Janeiro é dominada por ondas cuja variabilidade vai desde 1 até 6 metros de altura. O padrão de ondas mais comum para a área de estudo fica na ordem de 1 até 2 metros, com períodos variando de 8 a 12 segundos. As maiores ondulações que atingem a costa do município são provenientes das direções de SW, S e SE. Tal caracterização teve como referência os trabalhos de Pianca (2010) e Pereira e Klumb (2015).

Dentre as rochas constituintes da costa rochosa estudada destacam-se: ortognaisses, granitoides, silimanitabiotita gnaisse, metadiorito, metatonalito, metagabro, gnaisse granulítico e leucogranitos (CPRM, 2009). A presença de vários promontórios convexos dá um contorno arredondado a vários trechos da costa formando principalmente costões e falésias produzidas em escarpas de falha, fraturas e contatos litológicos. A forma sinuosa dos trechos faz com que alguns locais utilizados para lazer fiquem mais protegidos do ataque direto das ondas, enquanto outros fiquem mais suscetíveis à ação das mesmas.

A seleção dos locais e trechos a serem avaliados se baseou em reportagens sobre acidentes ocorridos na costa rochosa do município, entrevistas com membros do Grupamento Marítimo (G-Mar) do Corpo de Bombeiros Militar do Estado do Rio de Janeiro (CBMERJ) e excursões de campo ao longo da costa. Foram escolhidos, no total, nove trechos que possuem locais com livre acesso ao público frequentador, localizados entre Praia Vermelha e a Praia de Grumari (Figuras 2 e 3): 

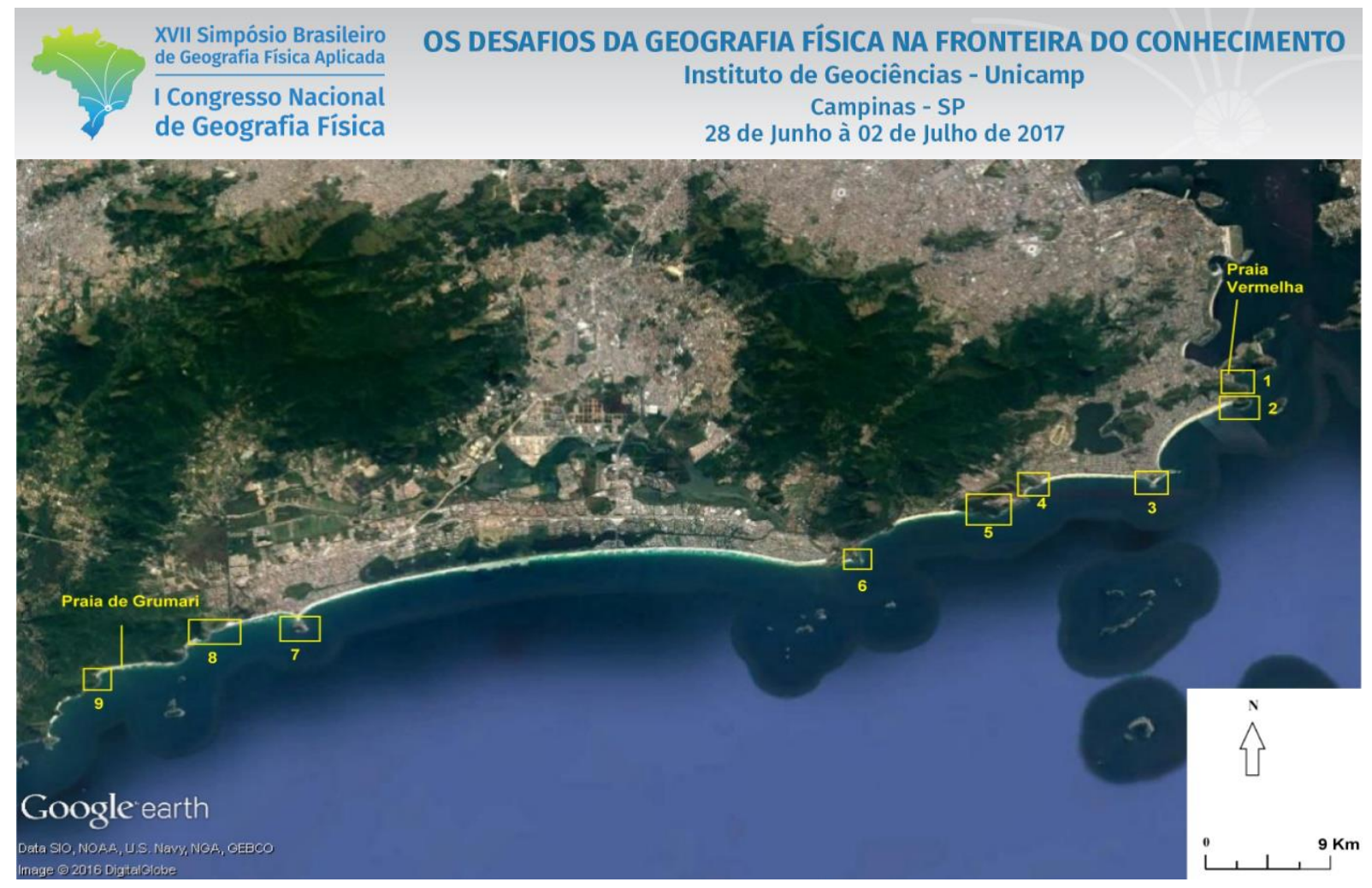

Figura 2 - Trechos da costa rochosa do município selecionados pelo estudo (Fonte: Google Earth).

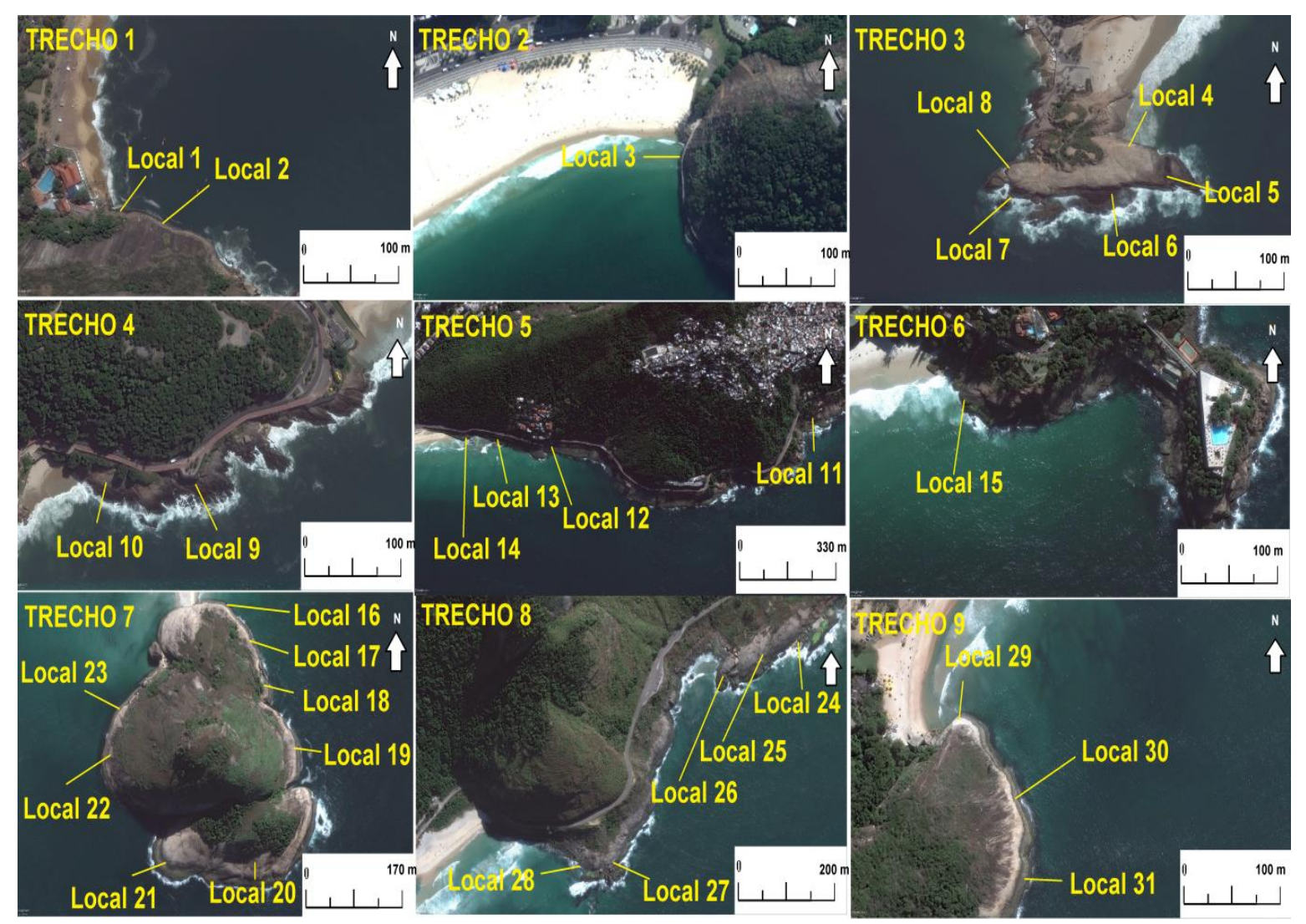

Figura 3 - Trechos selecionados pelo estudo (em maior detalhe) com os locais avaliados quanto ao grau de periculosidade (Fonte: Google Earth). 


\section{Metodologia}

\section{1 - Alcance das Lavagens}

Observações de campo possibilitaram caracterizar três faixas presentes nos locais da costa rochosa em questão onde ocorre a lavagem pelas ondas (Figura 4):

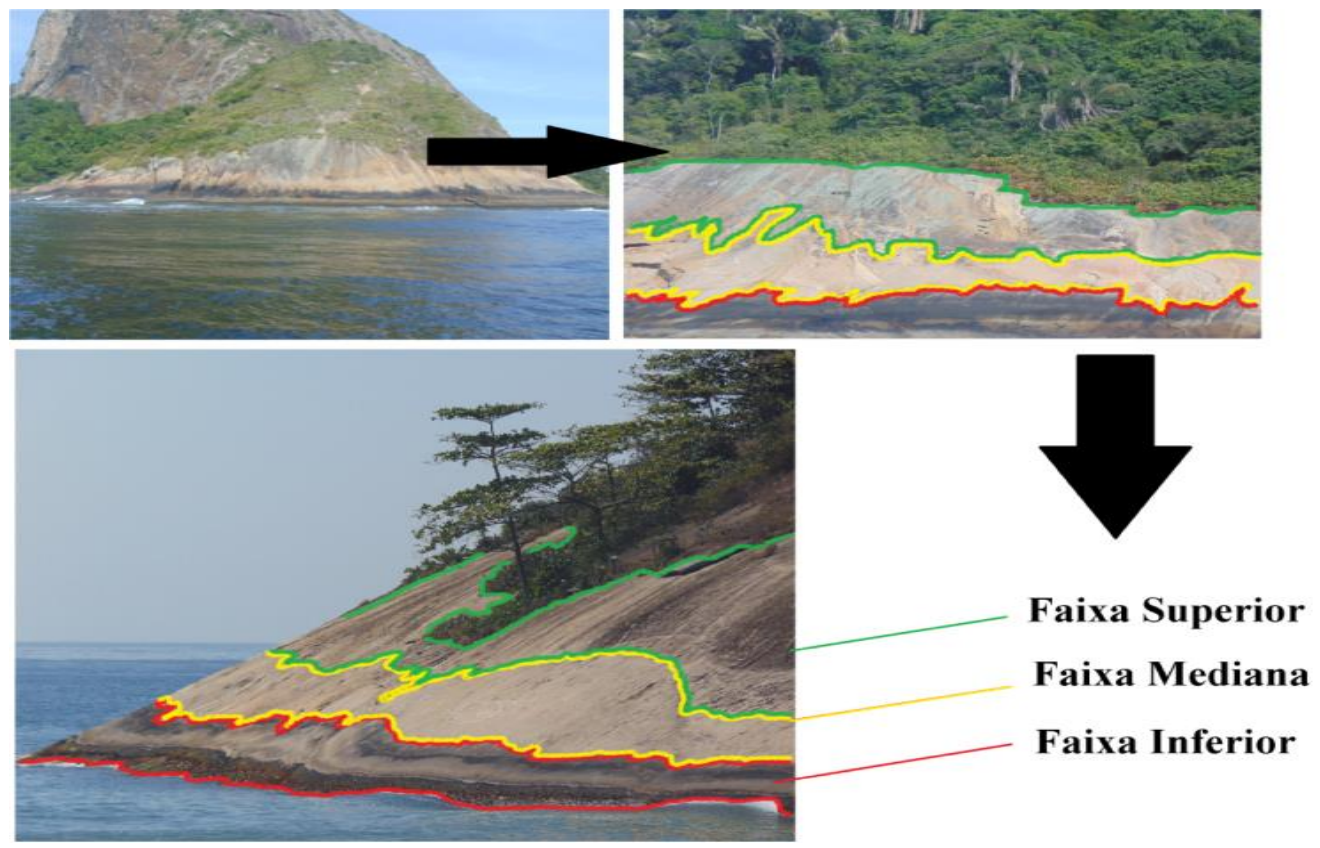

Figura 4 - Faixas onde ocorrem as lavagens nos locais da costa rochosa (Fotos: Felipe Miguel).

A Faixa Inferior é a primeira faixa a partir do nível do mar. Possui uma coloração bastante escura, sendo facilmente visível. É marcada pela zonação dos organismos bentônicos, como algas, cracas, mariscos, baratinha-do-mar, caramujos, entre outros. Foi observado que ondas acima de 2 metros são suficientes para inundar por completo tal faixa. A Faixa Mediana possui uma coloração mais clara e se caracteriza pela quase ausência de vegetação terrestre e organismos bentônicos. Tal faixa só é atingida pelas lavagens apenas em dias típicos de ressaca, com ondas ultrapassando $2 \mathrm{~m}$ de altura. A Faixa Superior possui uma coloração variando de verde musgo até marrom escuro devido à presença de líquens e cianofíceas. Também é marcada pela presença da vegetação terrestre rupestre, típica de costas rochosa de ambiente tropical. Tal faixa é raramente atacada pelas ondas. Só é atingida nos eventos mais extremos de tempestade, com ondas acima de $3 \mathrm{~m}$ de altura. As faixas serviram como indicador do alcance atingido pelas lavagens das ondas. Através das suas larguras foi possível identificar que locais sofrem as maiores lavagens e, assim, podem oferecer maior perigo aos usuários. Para este estudo foi analisada apenas a largura das faixas inferior e mediana. As 


\section{OS DESAFIOS DA GEOGRAFIA FÍSICA NA FRONTEIRA DO CONHECIMENTO \\ Instituto de Geociências - Unicamp \\ Campinas - SP \\ 28 de Junho à 02 de Julho de 2017}

mesmas foram medidas com trenas. Suas inclinações foram mensuradas com o uso de clinômetros (Figura 5):

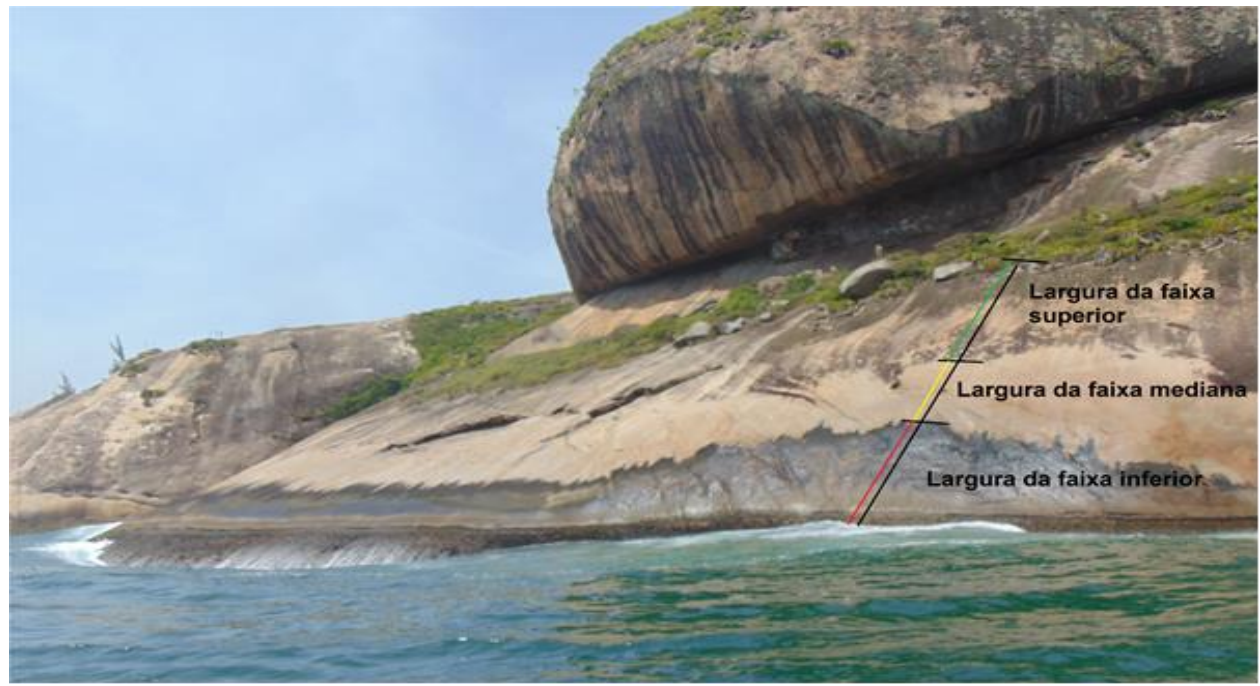

Figura 5 - Largura das faixas utilizadas como indicador do alcance atingido pela lavagem das ondas.

\section{2 - Rugosidade da Superfície}

Este estudo classificou a superfície dos locais de acordo com o nível de rugosidade encontrada. Foram tiradas fotografias ao longo da face de cada local selecionado, nas três faixas descritas. As canaletas e fendas foram medidas com uma fita métrica. A Figura 6 apresenta os três tipos de superfícies encontradas ao longo da costa rochosa do município:
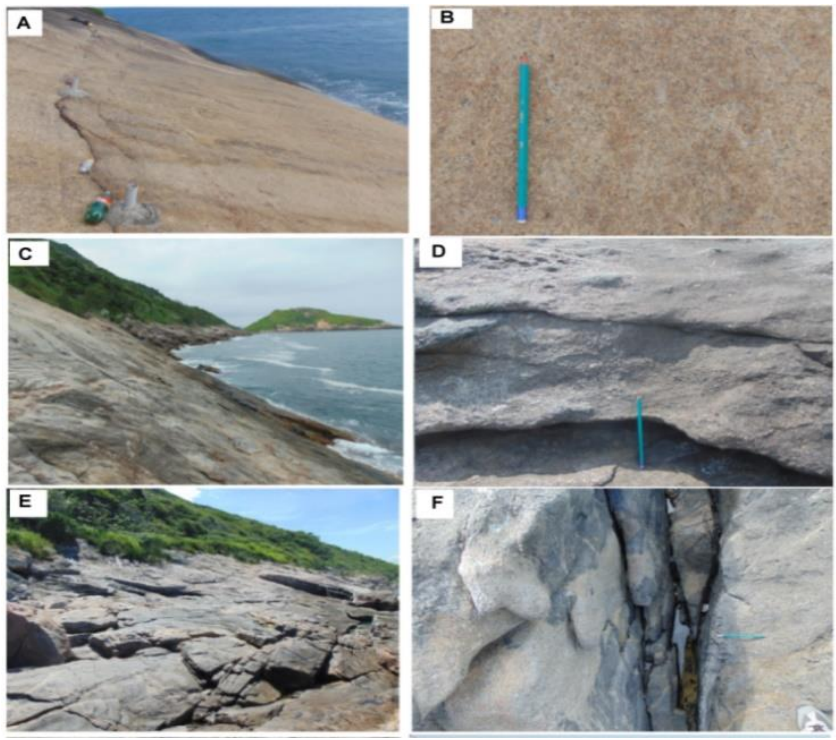

Figura 6 - Fotos A e B: Superfície Lisa - não apresenta fraturas, canaletas, depressões e ou tafones; Fotos C e D: Superfície Rugosa - apresenta fraturas com até 0,5 metro de largura e profundidade, além de tafones e pequenos 
"alvéolos"; Fotos E e F - Superfície Acidentada - apresenta fendas que ultrapassam 1 metro de comprimento, largura e profundidade. (Fotos: Felipe Miguel)

\section{3 - Grau de Exposição}

Dado ao contorno sinuoso de diversos trechos, alguns locais da costa rochosa não possuem face orientada frontalmente para a direção das ondulações de tempestade. Isso, de certa forma pode exercer influência na amplitude das lavagens. Resolveu-se então considerar a orientação geográfica dos locais como uma variável que pode determinar o grau de exposição dos locais frente ao ataque das ondas. A orientação de cada local foi então mensurada com a utilização de bússolas e imagens de satélite nos trechos mais recortados.

\section{4 - Avaliação da Periculosidade}

Entende-se aqui que o perigo oferecido pelos locais (P) está em função do alcance da lavagem realizada pelas ondas (AL), do grau de exposição dos locais $(\mathrm{Gex})$ e da rugosidade encontrada na superfície dos mesmos:

$$
P=f(A L, G e x, R)
$$

- $\quad \mathrm{P}=$ perigo oferecido;

- $\mathrm{AL}=$ alcance da lavagem (Indicado pela largura das faixas inferior e mediana);

- Gex = grau de exposição (Orientação dos locais frente à direção das ondas);

- $\mathrm{R}=$ rugosidade (superfície lisa, rugosa ou acidentada).

\section{Resultados}

\section{1 - Grau de exposição dos locais}

A análise conjunta da largura das faixas com a orientação geográfica dos locais possibilitou localizar áreas com diferentes graus de exposição às ondulações que atingem o litoral do município (Figura 7): 


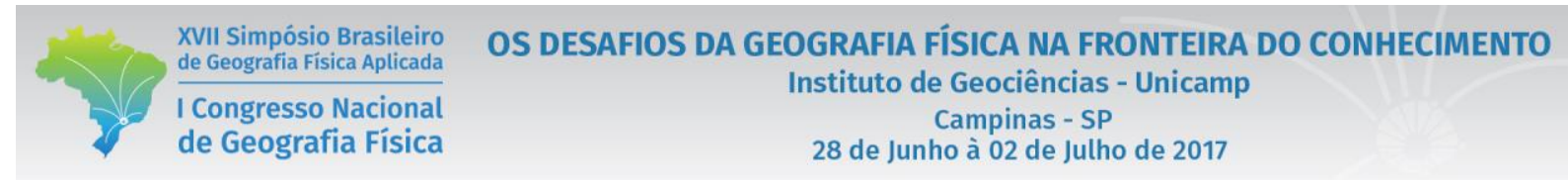

Faixa inferior

Faixa mediana
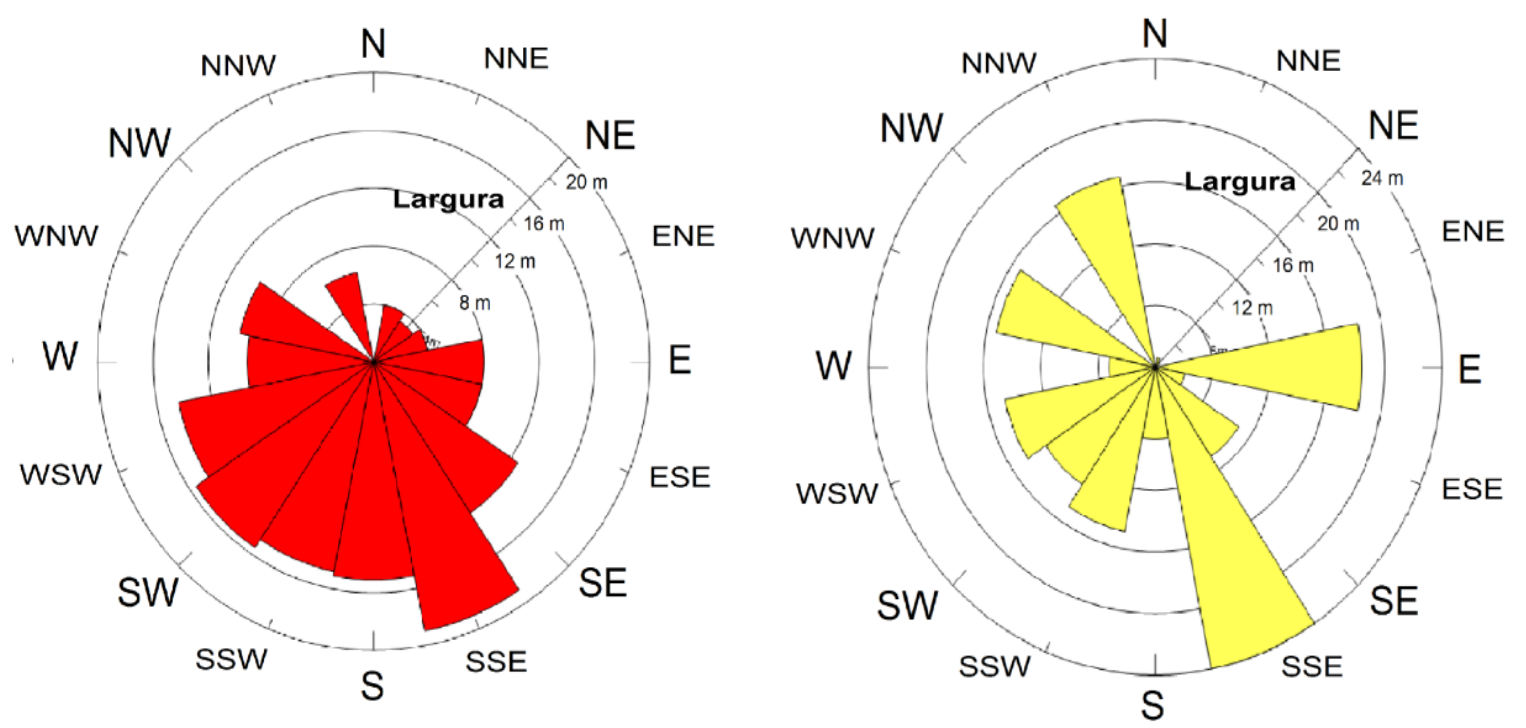

Figura 7 - Largura média das faixas inferior e mediana, de acordo com a orientação dos locais.

As faixas inferiores mais largas foram encontradas nos locais com orientações de SE, SSE, S, SSW, SW e WSW. Isto pode ser atribuído ao fato dos mesmos receberem de frente as ondulações vindas de SW, S e SE. As ondas atingem perpendicularmente suas faces, gerando lavagens de maior alcance vertical. Foram classificados como locais expostos. Já os locais com face voltada entre as direções de ESE, NNE e WNW, por não receberem frontalmente tais ondulações, apresentam faixa inferior com larguras menores, indicando um alcance mais baixo das lavagens. Foram considerados como locais semi-expostos. Com relação a largura da faixa mediana, os menores valores foram registrados nos locais com orientações de NE, NNE e ENE, direções opostas à das ondulações de tempestade provenientes dos quadrantes de Sul.

\section{2 - Inclinação}

A maioria dos locais apresenta face com inclinação média entre $20^{\circ}$ e $30^{\circ}$ (Figura 8): 


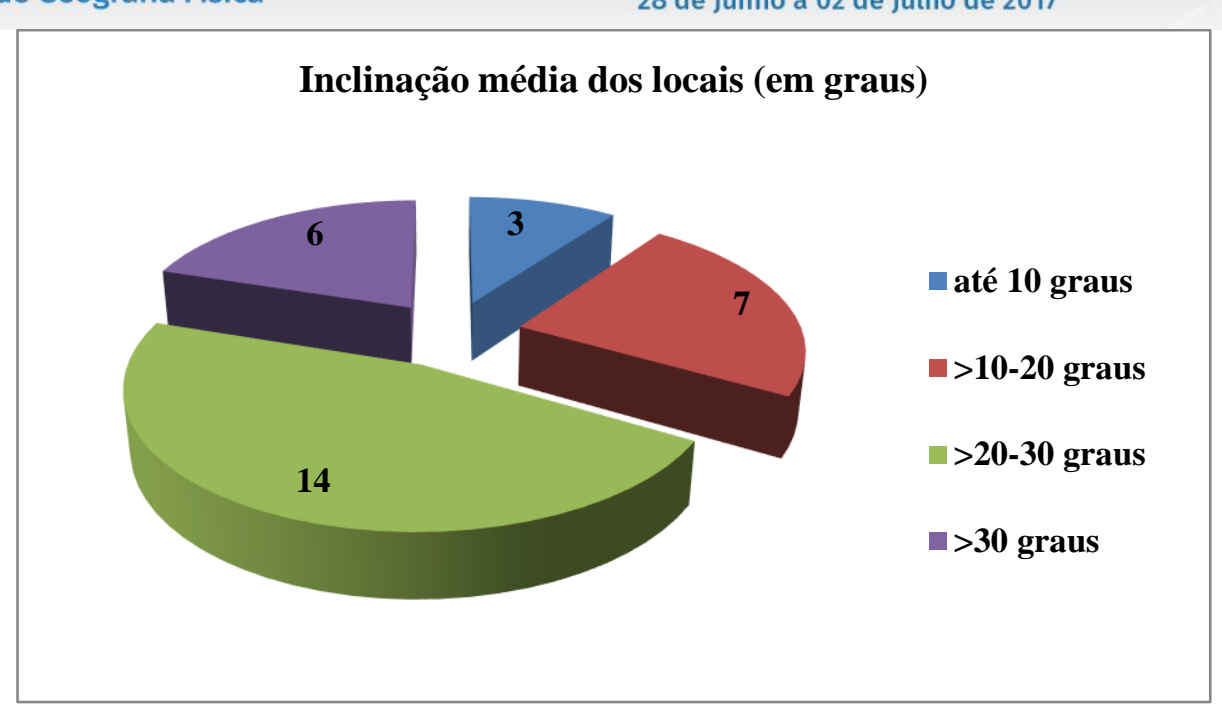

Figura 8 - Inclinação média encontrada nos locais

Faria (2016) encontrou valores parecidos em sua caracterização geomorfológica da costa rochosa do Estado do Rio de Janeiro. Os valores registrados pelo presente estudo, assim como o realizado por Faria (op.cit.), apontam para o grau de inclinação entre 20 e $30^{\circ}$ como sendo um padrão encontrado nos locais da costa rochosa do município. Este padrão difere do encontrado nas costas rochosas estudadas por outros pesquisadores do tema.

\section{3 - O alcance das lavagens e a influência da rugosidade}

A largura das faixas funcionou como uma marca permanente do alcance atingido pela lavagem das ondas. Através dos valores registrados foi possível localizar os locais onde ocorre maior lavagem e os locais mais protegidos da costa rochosa (figura 9): 

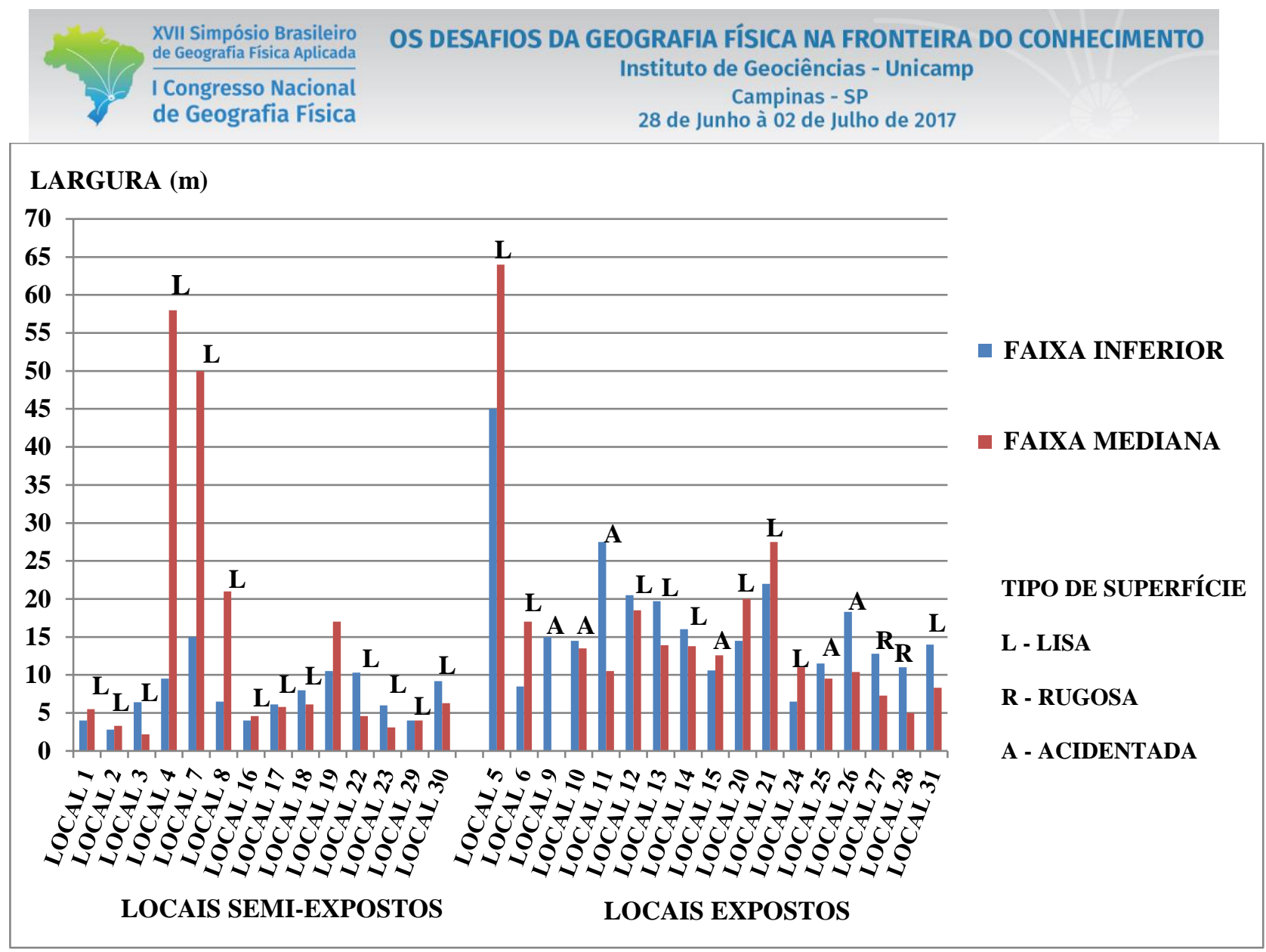

Figura 9 - Largura das faixas inferior e mediana dos locais estudados, com a classificação do tipo de superfície encontrada.

Enquanto em alguns locais a largura da faixa inferior não chega a $5 \mathrm{~m}$, em outros a mesma ultrapassa $20 \mathrm{~m}$. Alguns locais apresentam faixa mediana que ultrapassam $50 \mathrm{~m}$ de largura. $\mathrm{O}$ Local 5 foi o que apresentou as faixas mais largas indicando as lavagens de maior alcance. No Local 2 as faixas não ultrapassam $5 \mathrm{~m}$ de largura o que faz do mesmo o menos perigoso dentre todos os avaliados por este estudo.

A rugosidade da superfície, no geral, não exerce grande influência no alcance das lavagens. Alguns locais com superfície acidentada apresentam faixas mais largas que locais com superfície lisa. No entanto, a mesma foi considerada como um elemento potencializador do perigo oferecido aos usuários. Nos locais com superfície lisa as medições tiveram que ser conduzidas com maior atenção devido à menor aderência. Dentre os três tipos de superfície, a rugosa se mostrou a mais aderente. Isso pode ser atribuído à presença dos tafones, alvéolos e as fraturas de pequeno porte. A superfície acidentada também é escorregadia, mas a presença das fendas e buracos pode de algum modo, diminuir a probabilidade do usuário escorregar até o mar (Figura 10): 


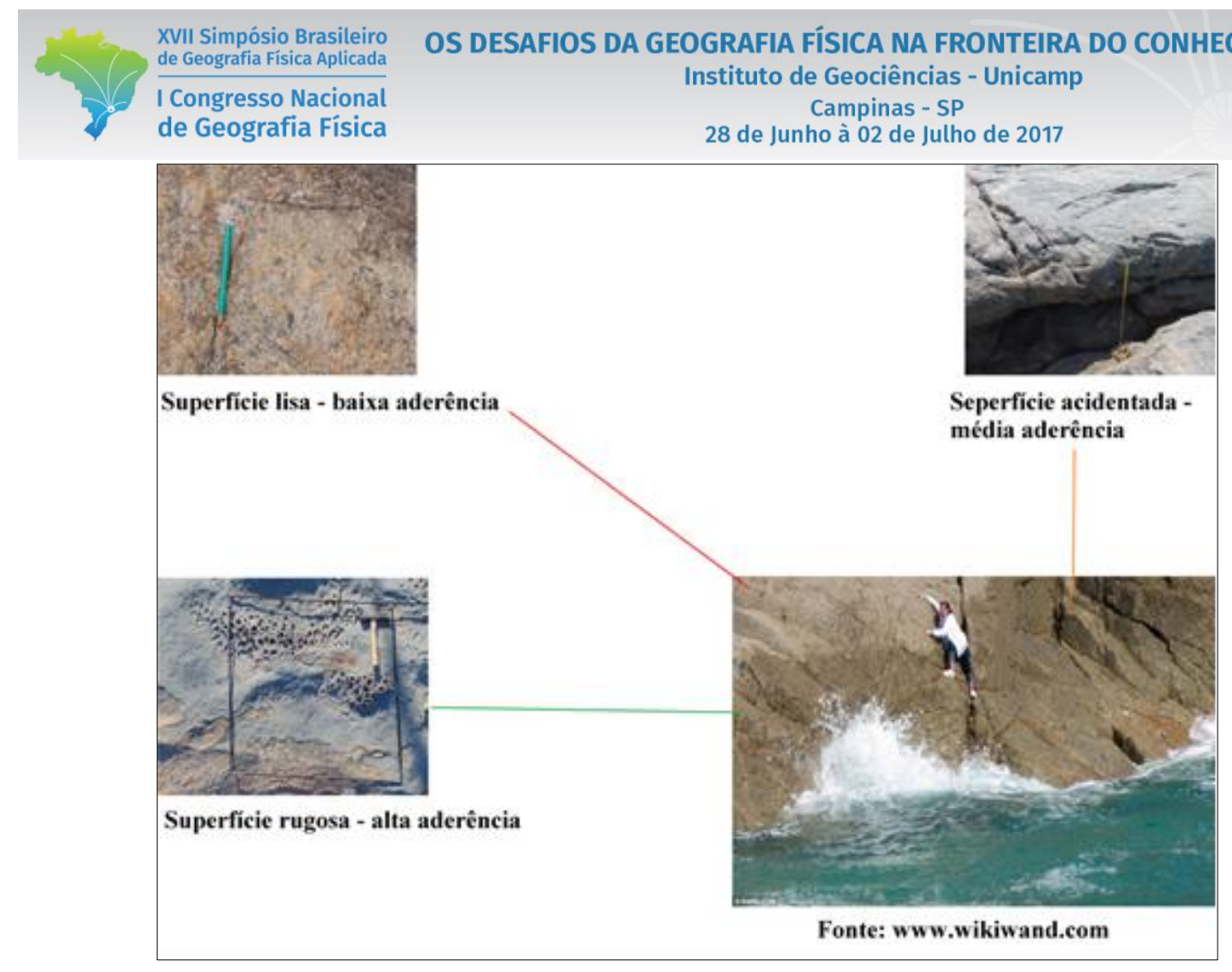

Figura 10 - Aderência relativa dos locais de acordo com a rugosidade.

A partir das informações trabalhadas, os locais foram divididos em quatro grupos, de acordo com o grau de periculosidade, a saber:

- Locais com grau de periculosidade baixo - Apresentam face com orientação semi-exposta e possuem as duas faixas com largura inferior a $10 \mathrm{~m}$;

- Locais com grau de periculosidade moderado - Apresentam face com orientação variando de semiexposta a exposta e possuem apenas uma das faixas com largura atingindo até $10 \mathrm{~m}$;

- Locais com grau de periculosidade elevado - Apresentam face com orientação semi-exposta e possuem as duas faixas com largura acima de $10 \mathrm{~m}$;

- Locais com grau de periculosidade muito elevado - Apresentam face com orientação exposta e possuem as duas faixas com largura acima de $10 \mathrm{~m}$.

As imagens a seguir correspondem aos trechos da costa rochosa do município que fizeram parte da pesquisa, com destaque para o grau de periculosidade e o tipo de superfície dos locais avaliados (Figura 11): 


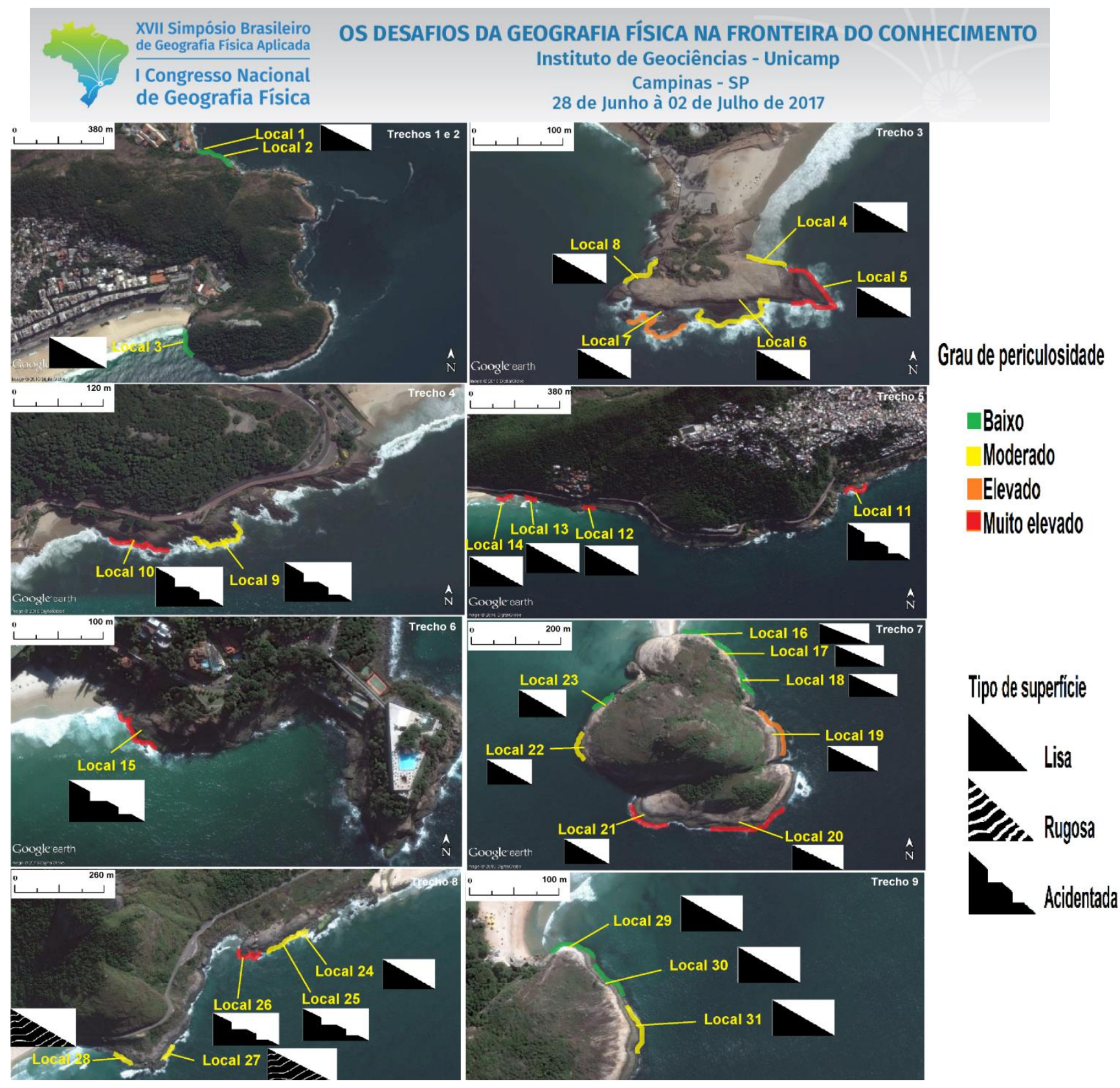

Figura 11 - Grau de periculosidade dos locais selecionados pelo presente estudo (Fonte: Google Earth).

\section{Conclusões}

Este estudo caracterizou aspectos ligados à morfologia de diversos locais frequentados da costa rochosa do município do Rio de Janeiro e suas interações com as ondas. Através dos parâmetros geomorfológicos e oceanográficos investigados foi possível avaliar o grau de periculosidade dos locais frequentados.

A largura das faixas funcionou para localizar tanto os locais que sofrem as maiores lavagens assim como os mais protegidos contra as ondulações provenientes dos quadrantes de Sul. A análise da orientação da face dos locais possibilitou conhecer melhor a dinâmica dos fluxos hídricos gerados pelas ondas ao longo da costa rochosa e, assim, inferir o grau de exposição dos mesmos. A rugosidade não determinou quais locais 
da costa rochosa sofrem maior lavagem das ondas. No entanto, a mesma pôde ser incluída como um elemento potencializador do perigo. $\mathrm{O}$ trabalho considera a aderência relativa das superfícies rochosas como mais uma informação que pode alertar sobre o risco do usuário escorregar e cair no mar.

A maioria dos locais frequentados da costa rochosa do município não possui sinalização advertindo contra os perigos oferecidos. As pouquíssimas placas alertando sobre os perigos oferecidos pelos locais frequentados carecem de informações específicas. O resultado desta pesquisa pode de certa forma, enriquecer a sinalização com mais informações a respeito da magnitude das lavagens, grau de exposição dos locais, aderência relativa da superfície e inclinação. O trabalho apresentado enxerga a conscientização do público frequentador como a medida mais eficiente na redução dos acidentes na costa rochosa do município do Rio de Janeiro.

\section{REFERÊNCIAS}

CPRM. Mapa Geológico na escala 1:100.000 .Folha Baía de Guanabara.SF23-Z-B-IV, 2009.

FARIA, A.P. Dinâmica dos Costões e Falésias Cristalinas do Estado do Rio de Janeiro. Revista Brasileira de Geomorfologia. Vol 17 (3), 2016.

KENNEDY, D.M.; SHERKER, S.; BRIGHTON, B. and WEIR, A., WOODROFFE, C.D. Rocky coast hazards and public safety: moving beyond the beach in coastal risk management. Ocean and Coastal Management 82, 2013, pp. 85 - 94.

PEREIRA, N.E.S. \& KLUMB, L.A. Analysis of the influence of ENSO phenomena on wave climate on the central coastal zone of Rio de Janeiro (Brazil). Revista de Gestão Costeira Integrada - Journal of Integrated Coastal Zone Management. 15(3):353-370, 2015.

PIANCA, C; MAZINNI, P.L.F. and SIEGLE, E. Brazilian offshore wave climate based on NWW3 reanalysis. Brazilian Journal of Oceanography, 58 (1), 2010, p. 53-70. 